\title{
Article \\ Research on Shear Behavior of Sand-Structure Interface Based on Monotonic and Cyclic Tests
}

\author{
Pei Zhang ${ }^{1}$, Shijia Ding ${ }^{1}$ and Kang Fei ${ }^{1,2, *}$ \\ 1 College of Civil Science and Engineering, Yangzhou University, Yangzhou 225100, China; \\ MZ120190770@yzu.edu.cn (P.Z.); MX120200563@yzu.edu.cn (S.D.) \\ 2 Institute of Geotechnical Engineering, Yangzhou University, Yangzhou 225127, China \\ * Correspondence: kfei@yzu.edu.cn
}

Citation: Zhang, P.; Ding, S.; Fei, K Research on Shear Behavior of Sand-Structure Interface Based on Monotonic and Cyclic Tests. Appl. Sci. 2021, 11, 11837. https://doi.org/ 10.3390/app112411837

Academic Editor: Yongxin Wu

Received: 11 November 2021 Accepted: 10 December 2021 Published: 13 December 2021

Publisher's Note: MDPI stays neutral with regard to jurisdictional claims in published maps and institutional affiliations.

Copyright: (c) 2021 by the authors. Licensee MDPI, Basel, Switzerland. This article is an open access article distributed under the terms and conditions of the Creative Commons Attribution (CC BY) license (https:// creativecommons.org/licenses/by/ $4.0 /)$.

\begin{abstract}
In order to study the shear behavior of the interface between sand and structure, a series of shear tests were carried out using an HJ-1 ring shear apparatus (Nanjing, China). First, through the monotonic shear tests, the loose sand and dense sand were sheared at the steel interface with different roughnesses. The results showed that when the interface was relatively smooth, the shear stressshear displacement curves of loose sand and dense sand both exhibit strain hardening characteristics. When the interface was rough, the dense sand showed strain softening. The initial shear stiffness of the sand-steel interface increased with the increase in normal stress, interface roughness, or sand relative density. Then, considering the influence of initial shear stress, through the cyclic shear test, this work analyzed the shape of the loading and unloading curves and the development law of cumulative normal deformation, and discussed the change of loading and unloading shear stiffness under different stress level amplitudes and the residual deformation generated during the cycle. The research results showed that loose sand and dense sand generally shrunk in volume during the cycle. The initial loading process was similar to the case of static loading. In the later dynamic loading process, the shear shrinkage per cycle was relatively small and continued to develop. Additionally, it was found that the unloading stiffness of the sand-steel interface is always greater than the initial loading stiffness. As the number of cycles increases, the loading stiffness increases, and it may eventually approach the unloading stiffness.
\end{abstract}

Keywords: sand-structure interface; shear behavior; monotonic and cyclic tests; interface roughness

\section{Introduction}

The problem of the interaction between soil and structure is widespread in geotechnical engineering [1-9], such as the interaction between piles and surrounding soil, underground diaphragm wall and soil behind the wall, etc. Due to the great difference between the stiffness of soil and structure, under the action of external load, discontinuous phenomena such as shear slippage, dislocation and disengagement may occur at the contact surface. Therefore, the shear stiffness, strength, deformation and other mechanical properties of the contact surface have become one of the core topics in the study of the interaction between soil and structure [10-16].

To date, scholars have conducted research on the contact surface between soil and structure through static tests. Uesugi and Uchikawa [17] employed the direct simple shear test to investigate the shear behavior of the soil-structure interface. Potyondy [18] was the first to use an improved shear box to carry out interfacial shear tests to study the problem of interfacial friction between sand and structural materials. Hamid and Miller [19] used a direct shear box to demonstrate the shear strength of the interface between lean clay and steel and concluded that normal stress may influence shearing resistance for both smooth and rough interfaces. Considering that there may be cyclic loading in actual engineering, such as seismic load, wave load, etc., Desai et al. [20] introduced a two-degree-of-freedom cyclic direct shear instrument for cyclic testing and modeling research on the sand-concrete 
interface. The experimental results showed that the peak or mobilized shear stress increased with the number of cycles. However, the increase for higher density was not as rapid as that for the lower density. This implied that, in general, for cohesionless soils, the interface response hardened with an increasing number of cycles, and the rate of such hardening decreased with an increasing number of cycles. Kawk et al. [21] constructed a modified multi-purpose interface apparatus to replace the field test of the pile-soil interface shear test. Additionally, he found a consistent conclusion with Desai, which was that the increase in the number of test cycles caused the shear stiffness of the interface to change. However, the effect of initial shear stress was ignored in their experiments. In many engineering applications, the shear stress already existed before the dynamic load was applied. For example, under cyclic loads such as seismic loads, wave loads, and traffic loads, the shear stress of the contact surface between the pile and the soil around the pile might fluctuate around the initial shear stress. However, the difference of loading and unloading stiffness and the accumulated residual deformation are important factors to be considered in engineering design.

According to Masing's law [22], if unloading occurs under the initial shear stress, the unloading stiffness is consistent with the loading stiffness. Loading and unloading under the condition of constant amplitude forms a closed hysteresis loop. If, according to Pyke's loading and unloading criteria [23], the stiffness of each load is only related to the current turning point (Figure 1), this behavior will produce the obvious accumulation of residual plastic deformation, which is similar to the ratchet effect [24-28]. Additionally, the applicability of the two models to the experimental results needs to be verified. Therefore, it is of great engineering significance to study the cyclic shear behavior of the interface between sand and structure considering the initial shear stress.

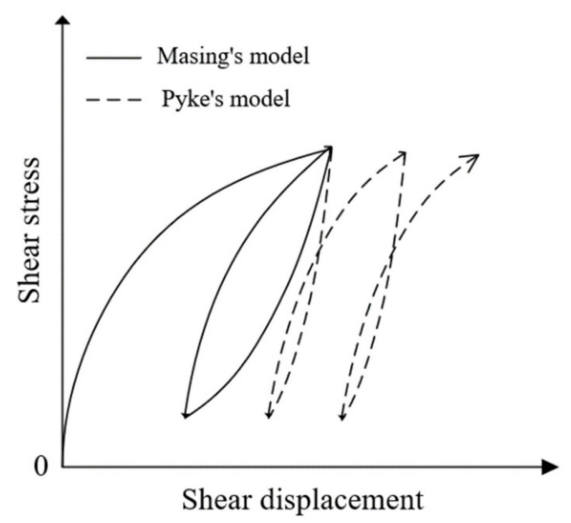

Figure 1. Schematic diagram of loading and unloading modulus.

This paper aimed to study the cyclic shear behavior of the sand-structure interface considering the initial shear stress. The structure of this paper was mainly divided into two parts of static and dynamic tests, as well as the analysis and discussion of the results. In the first part, a series of monotonic shear tests were carried out with HJ-1 ring shear apparatus (Nanjing, China). Through this series of tests, the factors affecting the shear stiffness were discussed, and the dilatancy and shrinkage of the sand were found. According to the empirical formula [29] of initial shear modulus proposed by the predecessors and fitting the test results, the formula for calculating the initial shear stiffness of the interface between sand and structure was proposed. Then, in the second part, the cyclic shear tests were conducted on the basis of considering the influence of the initial shear stress. This work showed the shape of the loading and unloading curves, as well as the development law of normal deformation. This study clarified the relationship between loading stiffness and unloading stiffness, as well as the changing law of loading stiffness with cycle. The behavior of cyclic accumulated residual deformation was analyzed. In addition, comparative tests of cyclic shear on the sand-steel interface under different stress level amplitudes were carried out. This work discussed the variation law of loading and 
unloading stiffness and its residual deformation under different stress level amplitudes. This research is helpful to improve our understanding of sand-structure contact in practice.

\section{Materials and Experimental Process}

\subsection{Test Soil}

The sand used in this test was taken from Fujian, China, and its particle grading curve is shown in Figure 2. Table 1 lists the properties of the sand.

Table 1. Properties of sand used in this study.

\begin{tabular}{cccccc}
\hline $\begin{array}{c}\text { Average Grain } \\
\text { Diameter } D_{50}[\mathrm{~mm}]\end{array}$ & $\begin{array}{c}\text { Specific } \\
\text { Gravity } G_{s}[-]\end{array}$ & $\begin{array}{c}\text { Coefficient of } \\
\text { Uniformity } C_{u}[-]\end{array}$ & $\begin{array}{c}\text { Coefficient of } \\
\text { Curvature } C_{c}[-]\end{array}$ & $\begin{array}{c}\text { Maximum Void } \\
\text { Ratio } e_{\max }[-]\end{array}$ & $\begin{array}{c}\text { Minimum Void } \\
\text { Ratio } e_{\min }[-]\end{array}$ \\
\hline 0.34 & 2.65 & 1.54 & 0.95 & 0.85 & 0.52 \\
\hline
\end{tabular}

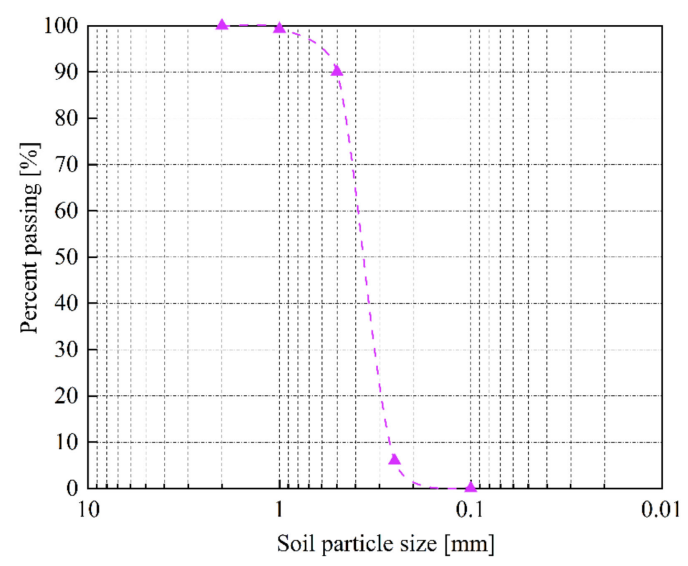

Figure 2. Particle size distribution of sand.

\subsection{Test Apparatus}

This research used an HJ-1 ring shear apparatus (Nanjing TKA Technology Co., Ltd., Nanjing, China), as shown in Figure 3a. The test apparatus had the advantages of constant contact area during shearing, uniform stress and strain, and large shear displacement. In order to realize the interface shear test, the concave-convex blade originally located at the bottom of the shear box for fixing the specimen was taken out, and then the prefabricated ring steel of the corresponding size was put in and fixed with screws. This was to ensure that the steel ring and the base would not move relative to each other during shearing. Therefore, the HJ-1 ring shear apparatus could study the interface shear characteristics of two different materials and supported the shear test in both clockwise and counterclockwise directions, as well as controlled the shear modes of equal stress and equal displacement. These functions were not available in traditional ring shear apparatus. This research did not consider drainage conditions, and mainly studied the shear behavior of the interface between dry sand and structure. The sample size in the ring shear box was $100 \mathrm{~mm}$ (outer diameter) $\times 60 \mathrm{~mm}$ (inner diameter) $\times 20 \mathrm{~mm}$ (height). Figure $3 \mathrm{~b}$ showed a schematic diagram of the placement of sand and steel in the ring shear box. The bottom of the ring shear box was connected with a torque sensor, the shear box was rotated by applying torque to cut, and the normal load was applied by the counterweight. The vertical displacement monitoring platform was installed above the normal stress sensor. The maximum normal stress that could be applied was $900 \mathrm{kPa}$, and the maximum torque was $300 \mathrm{~N} \cdot \mathrm{m}$. After the instrument was connected to the computer, the shearing torque could be automatically collected. The conversion relationship between shear stress and torque was as follows:

$$
\tau=\frac{3 M}{2 \pi\left(R_{2}^{3}-R_{1}^{3}\right)}
$$


where $\tau$ is the shear stress; $M$ is the shear torque; and $R_{1}$ and $R_{2}$ are the inner radius and outer radius of the sand sample, respectively.

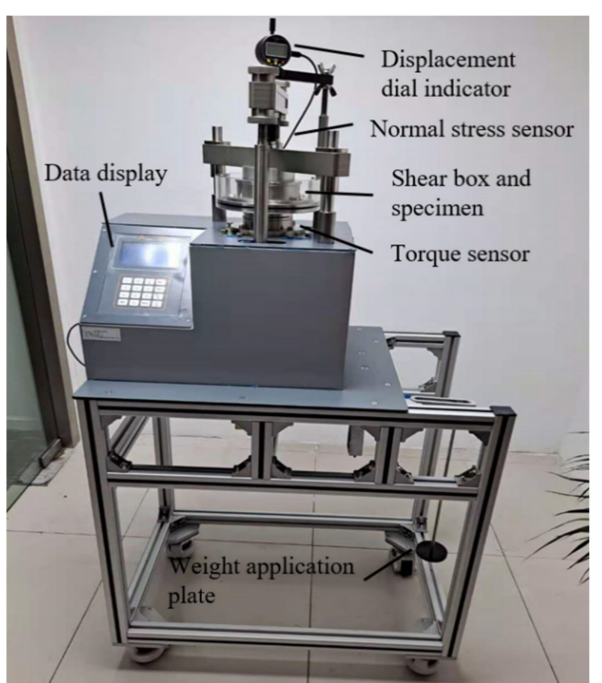

(a)

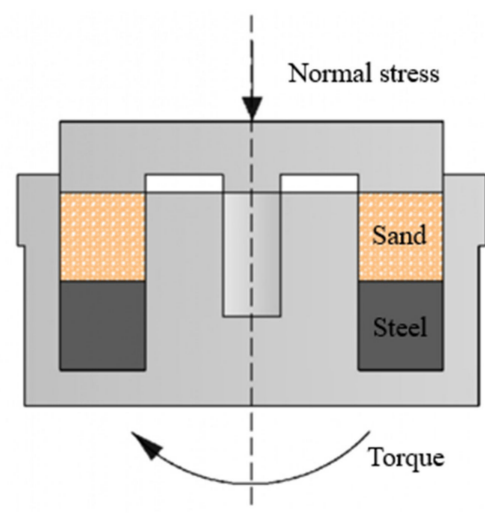

(b)

Figure 3. Interface shear testing apparatus. (a) The HJ-1 ring shear apparatus. (b) Schematic diagram of shearing of sand-steel interface.

\subsection{Roughness of Structure Interface}

In this study, the surface roughness of the stainless-steel ring was specially prefabricated. The method was to cut the sandpaper into the same size as the surface of the steel ring and paste it on the surface of the steel ring with epoxy resin to simulate different interface roughness levels. The roughness of the contact surface of the stainless-steel ring made by this method was relatively uniform. In this paper, the different grit sizes of sandpaper were used as the evaluation parameters of the simulated sand-steel interface roughness (sandpaper grit \#120, sandpaper grit \#60). The grit size of the sandpaper indicated the grain size or thickness of the surface material of the sandpaper. Larger grit size implied that the material had fine particle size, and the undulation degree of the sandpaper surface profile was relatively small; that is, the interface roughness was relatively small. The opposite was true for smaller grit size, indicating that the undulation degree of the sandpaper surface profile was relatively large; that is, the interface roughness was relatively large. In addition, there was a steel ring without sandpaper as a relatively smooth interface. It should be noted that the smooth interface was not completely without roughness. It was just that the undulation of the steel surface was much smaller than that of the sand surface. Therefore, it could be approximated as a smooth contact surface. In this way, three kinds of roughness $\left(R_{n 1}, R_{n 2}, R_{n 3}\right)$ of the steel ring interface were produced, which corresponded to a relatively smooth interface, a medium rough interface and a rough interface, as shown in Figure 4.

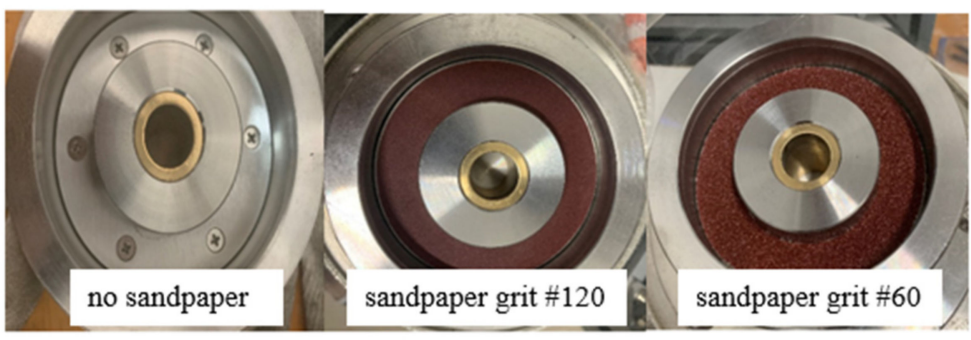

(a)

(b)

(c)

Figure 4. Three kinds of roughness interface formed by sandpaper and steel ring: (a) $R_{n 1}$ : relatively smooth interface; (b) $R_{n 2}:$ medium rough interface; (c) $R_{n 3}$ : rough interface. 


\subsection{Experimental Programs}

The relative density, vertical confinement pressure and interface roughness of the sand samples for the interface shear test are listed in Table 2.

Table 2. Schemes of monotonic shear tests and cyclic shear tests.

\begin{tabular}{ccc}
\hline Types of Interface Shear & Monotonic Shear & Cyclic Shear \\
\hline Relative density of sand $D_{r}$ & $0.3(e=0.79)$ & $0.3(e=0.79)$ \\
Vertical confining pressure $\sigma[\mathrm{kPa}]$ & $0.9(e=0.56)$ & $0.9(e=0.56)$ \\
Interface roughness $R_{n}$ & $200,300,400$ & $200,300,400$ \\
& $R_{n 1}, R_{n 2}, R_{n 3}$ & $R_{n 1}, R_{n 3}$ \\
\hline
\end{tabular}

Two series of tests were conducted in this study, one was the monotonic shear test of sand-steel interface, which considered the influence of factors such as normal stress, interface roughness, and relative density of sand on the test. In the shear test studies of sand conducted by Punetha [30], Wang [31] and Kou [32] and many other researchers, the shear rate was $0.2-1.2 \mathrm{~mm} / \mathrm{min}$. In order to ensure the stability and reliability of the test data, this test controlled the shear rate at $0.3 \mathrm{~mm} / \mathrm{min}$ and stopped the test when the fixed shearing displacement had reached $10 \mathrm{~mm}$. The other was the cyclic shear test of sand-steel interface considering the initial shear stress. This is to ensure the consistency and reliability of the comparison between results of static and dynamic tests. Therefore, the shear rate of the cyclic shear tests was also controlled at $0.3 \mathrm{~mm} / \mathrm{min}$. The initial shear stresses were set to $30 \%, 60 \%$, and $90 \%$ of the peak shear stress, and then unloaded so that each set of tests were cycled 10 times.

\section{Monotonic Shear Tests}

\subsection{Test Results}

\subsubsection{Shear Stress-Shear Displacement Curve}

As shown in Figure 5a, when the interface roughness is relatively smooth, the shear stress-shear displacement curve of loose sand or dense sand first grows nonlinearly and then tends to be gentle; that is, the characteristics of strain hardening. The maximum shear stress almost always corresponds to a shear displacement of about $3 \mathrm{~mm}$. Figure 5 e shows the interface under rough conditions. For dense sand, there will be obvious peak shear stress; that is, strain softening. For loose sand, the trend is similar to that when the interface is relatively smooth. The performance of the interface roughness at $R_{n 2}$ is similar to that of $R_{n 3}$, but the softening phenomenon is not so obvious. It is observed that as the normal stress or interface roughness increases, the softening phenomenon exhibited by the dense sand becomes more intense.

If the tangent slope of the initial nonlinear growth phase in the shear stress-shear displacement curve is defined as the initial shear stiffness, whether loose sand or dense sand is on the same roughness interface, as the normal stress increases, the initial shear stiffness increases accordingly, and the shear strength also increases. Under the same normal stress, as the interface roughness increases, its shear strength also increases.

\subsubsection{Shear Displacement-Normal Displacement Curve}

Figure $5 \mathrm{~b}$ shows that when the interface is relatively smooth, the loose sand exhibits a reduction in volume. Additionally, the greater the normal stress, the greater the amount of shear shrinkage. This test stipulates that the normal deformation is the positive value of the upward deformation. When the normal stress increases to $400 \mathrm{kPa}$, the normal displacement stabilizes at approximately $-0.35 \mathrm{~mm}$. In this case, the volume of dense sand hardly changes. For the case of $R_{n 3}$ (Figure $5 \mathrm{f}$ ), loose sand still shows shear shrinkage, but the volume shrinkage of sand is greater. Similarly, when the normal stress is $400 \mathrm{kPa}$, the normal displacement reaches about $-0.9 \mathrm{~mm}$. In this case, dense sand appears as shear shrinkage at the beginning, and then it undergoes dilatancy. Additionally, with the increase in normal stress, the amount of shearing increases continuously, and the maximum normal 
displacement is stabilized at about $0.5 \mathrm{~mm}$. For the case of $R_{n 2}$, the curve behavior is consistent with that when the interface is rough, but the phenomenon of shear shrinkage is not so severe. Additionally, it is also found that with the increase in the interface roughness, the shear shrinkage of loose sand and the shear dilatancy of dense sand are more obvious.

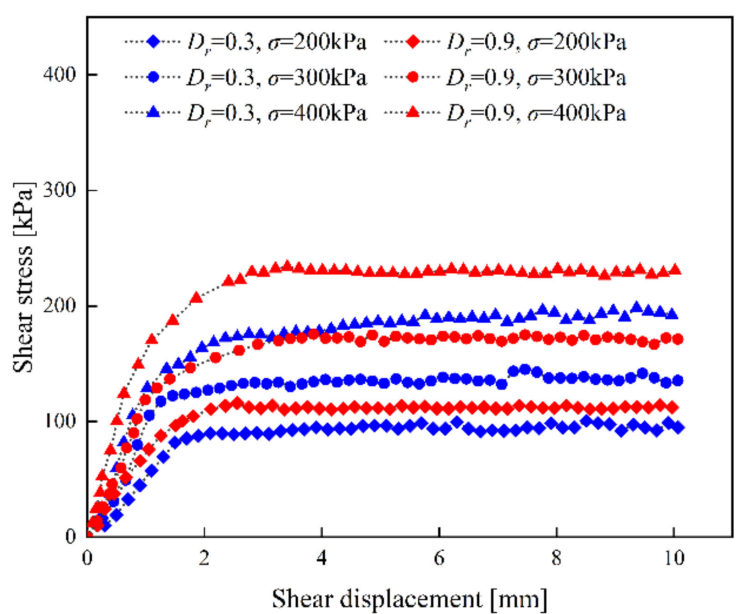

(a)

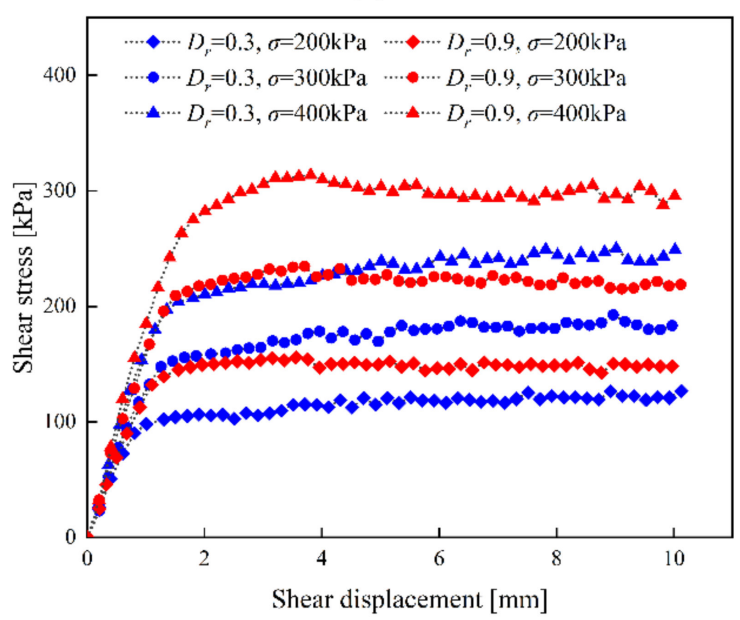

(c)

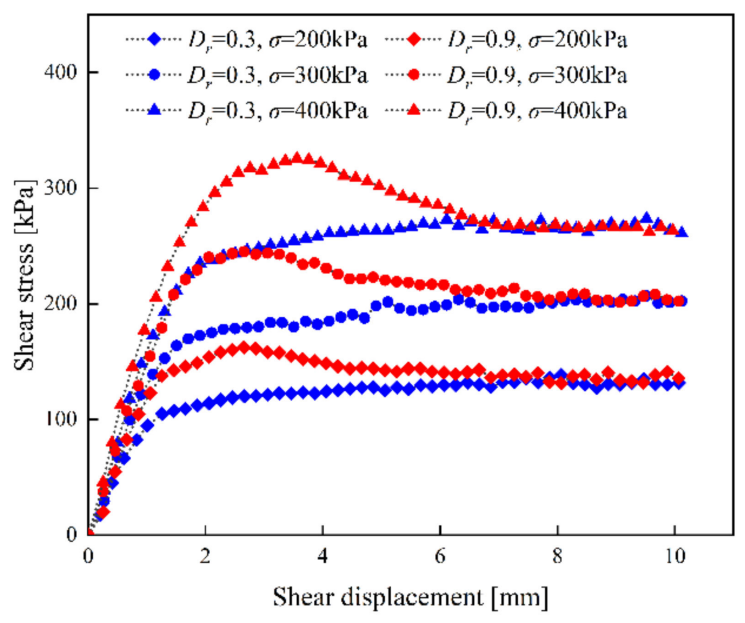

(e)

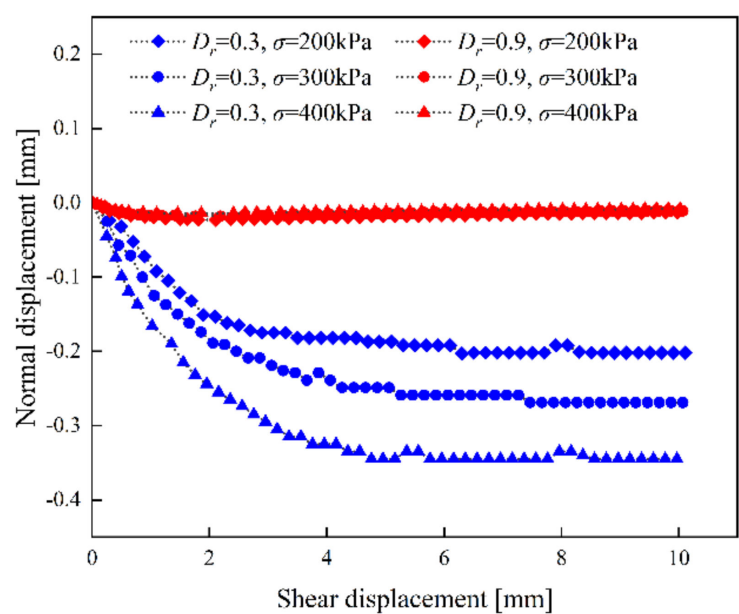

(b)

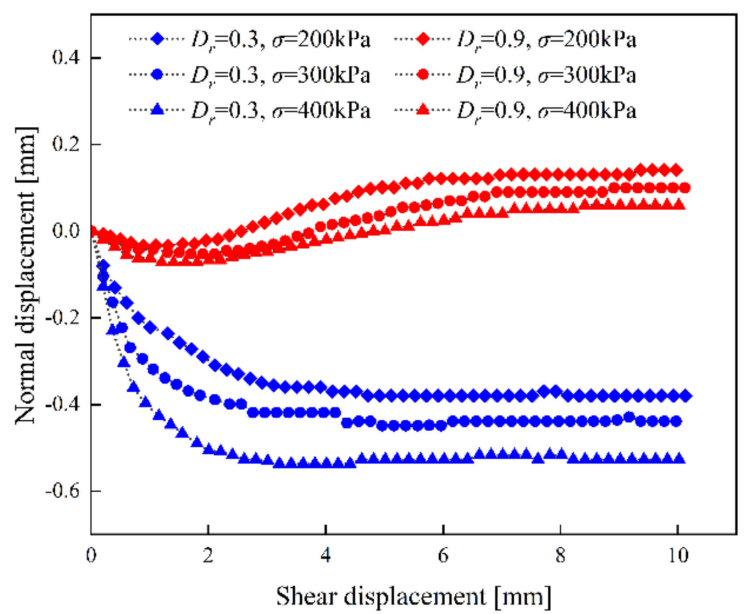

(d)

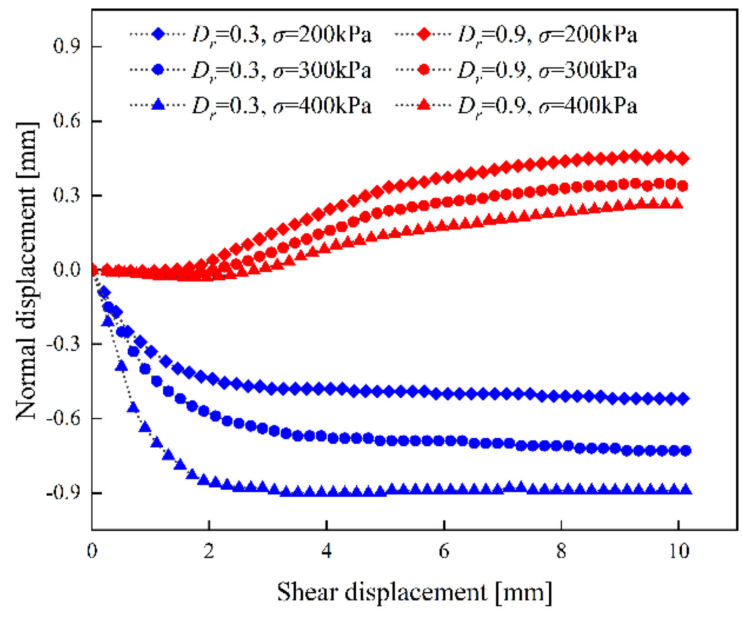

(f)

Figure 5. Comparison of morphological characteristics of sand-steel interface in monotonic shear test: $(\mathbf{a}, \mathbf{b}) R_{n 1} ;(\mathbf{c}, \mathbf{d}) R_{n 2} ;(\mathbf{e}, \mathbf{f}) R_{n 3}$. 


\subsection{Analysis and Discussion}

3.2.1. The Influence of Interface Roughness on Shear Strength

The interface shear strength of sand-steel with different roughness is fitted with the Mohr Coulomb criterion. Table 3 lists the shear strength parameters determined by the interface peak value and the residual shear strength fitting envelope.

Table 3. Strength parameters of monotonic shear at the sand-steel interface.

\begin{tabular}{cccc}
\hline \multirow{2}{*}{ Interface Strength Type } & Peak Friction Angle & Residual Friction Angle \\
\cline { 2 - 4 } & & $\boldsymbol{\varphi}_{\mathbf{0}}\left[^{\circ}\right]$ & $\boldsymbol{\varphi}_{r}\left[^{\circ}\right]$ \\
\hline \multirow{2}{*}{$R_{n 1}$} & $D_{r}=0.3$ & 24.70 & 24.50 \\
& $D_{r}=0.9$ & 30.28 & 29.64 \\
\hline \multirow{2}{*}{$R_{n 2}$} & $D_{r}=0.3$ & 30.24 & 30.07 \\
& $D_{r}=0.9$ & 38.76 & 35.43 \\
\hline \multirow{2}{*}{$R_{n 3}$} & $D_{r}=0.3$ & 33.54 & 33.23 \\
& $D_{r}=0.9$ & 39.18 & 33.82 \\
\hline
\end{tabular}

It is observed that when $R_{n}$ increases from $R_{n 1}$ to $R_{n 2}$, the peak friction angle of loose sand and dense sand increases by $5.54^{\circ}$ and $6.78^{\circ}$, respectively, and the residual friction angle of the interface also increases significantly. However, when $R_{n}$ increases from $R_{n 2}$ to $R_{n 3}, \varphi_{0}$ of loose sand increases from $30.24^{\circ}$ to $33.54^{\circ}$, while the interface of dense sand only increases by $0.42^{\circ}$. Additionally, the friction angle corresponding to the residual strength of the dense sand interface decreased slightly $\left(\varphi_{r}=35.43^{\circ}\right.$ to $\left.33.82^{\circ}\right)$. This shows that the roughness of the structural surface has a great influence on the strength of the interface. On the one hand, the shear strength parameter increases with the increase in the roughness of the structural surface, but the growth rate is gradually reduced. However, when the interface roughness is increased to $R_{n 2}$ and then increased, the peak friction angle of the interface hardly increases, which is especially significant for the dense sand interface. This also verified the results of Su's [33] experimental research. In his research, he found a critical value of relative roughness, the critical roughness $\left(R_{c r}\right)$. Additionally, the peak friction angle could no longer be readily enlarged when $R_{n}$ was beyond $R_{c r}$. Moreover, the shear shrinkage and dilatancy are more severe. On the other hand, as the roughness of the contact surface continues to increase, the difference between $\varphi_{0}$ and $\varphi_{r}$ of the dense sand-steel interface also increases. This also reflects that the rougher the interface between the relatively dense sand and the structure, the stronger the softening trend.

\subsubsection{Initial Shear Stiffness}

Figure 6 shows the results of initial shear stiffness of loose sand and dense sand with different interface roughness. The abscissa is $F(e) P_{a}\left(\sigma / P_{a}\right)^{0.5}$, and the ordinate is $K_{i n}$. It can be found that the fitting results of three interface roughness are three parallel lines. With reference to the empirical formula for the initial shear modulus of sand [29], a formula for calculating the initial shear stiffness of the interface between sand and structure is proposed:

$$
K_{i n}=A F(e) P_{a}\left(\frac{\sigma}{P_{a}}\right)^{0.5}+B
$$

where $F(e)$ is the void ratio function, $F(e)=(2.17-e)^{2} /(1+2 e), \sigma$ is the normal stress, and $P_{a}$ is atmospheric pressure, which is $101 \mathrm{kPa}$. $A$ and $B$ are fitting parameters to the test results, both of which are related to the interface roughness. $A$ is the amplitude of initial shear stiffness increasing with $F(e) P_{a}\left(\sigma / P_{a}\right)^{0.5}$, reflecting the influence of interface roughness on shear stiffness when shear stress is present. $B$ represents the influence of interface roughness on shear stiffness when there is no shear stress. This may be due to the presence of similar bite forces after the sand surface is in contact with the steel surface. 


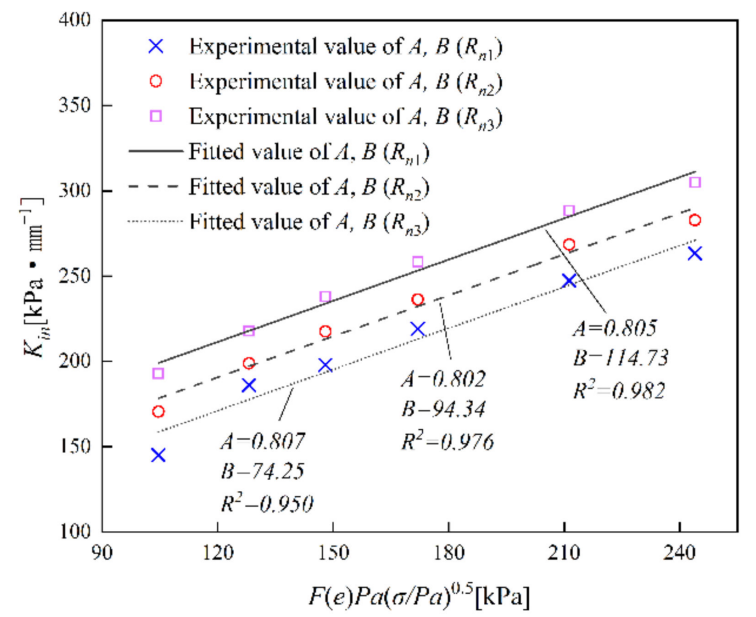

Figure 6. Fitting results of initial shear stiffness under different interface roughness.

It can be seen from Figure 6 that the value of parameter $A$ is almost unchanged, and they are all around $0.8 \mathrm{~mm}^{-1}$. The main factor that affects the roughness of the interface is parameter $B$. The greater the value of $B$, the greater the roughness of the interface, resulting in greater initial shear stiffness. It can also be found that as the normal stress or the relative density of sand increases, both affect the initial shear stiffness of the sand-steel interface. This is consistent with the law observed in the shear stress-shear displacement curve above.

\section{Cyclic Shear Tests}

\subsection{Test Results}

\subsubsection{The Relationship between Shear Displacement and the Shear Stress Ratio}

The loose sand and dense sand are subjected to a half-period cyclic shear test at two different roughness interfaces $\left(R_{n 1}, R_{n 3}\right)$. This work was carried out in 12 groups. Each group was divided into three tests, which were the $30 \%, 60 \%$ and $90 \%$ of the peak shear stress loading and unloading tests. Figure $7 \mathrm{a}-\mathrm{c}$ show three sets of tests, all of which show the relationship between shear displacement and shear stress ratio. They are the test results of loose sand with different normal stress on the relatively smooth interface. The expression of the shear stress ratio $\left(P_{\tau}\right)$ is as follows

$$
P_{\tau}=\frac{\tau}{\tau_{p}}
$$

where $\tau$ is the interface shear stress, and $\tau_{p}$ is the interface peak shear stress.

It is observed that the loading and unloading curves of loose sand on the relatively smooth interface are not closed under the three stress level amplitudes. Among them, the stress level amplitude of $90 \%$ is the most significant. This means that during the cyclic shearing process, residual deformation occurs at the loose sand interface. The other nine groups of trials also have a similar curve shape trend, which is not shown here. The difference is that the loading and unloading hysteresis curve of dense sand is tighter than that of loose sand. In particular, the stress level amplitudes of $30 \%$ and $60 \%$ are close to the closed hysteresis curve. In the case of a rough interface, the shape of the loading and unloading hysteresis curve of loose sand or dense sand is denser than that when the interface is relatively smooth. It shows that only when the stress level amplitude is $90 \%$ is the dense sand interface similar to that of loose sand, and the residual deformation occurs in the cycle. The reason why the loading and unloading hysteresis curve is not closed is mainly due to the difference in shear stiffness between loading and unloading. Therefore, it is necessary to further excavate and analyze the residual deformation and load-unload shear stiffness generated during the cycle. 


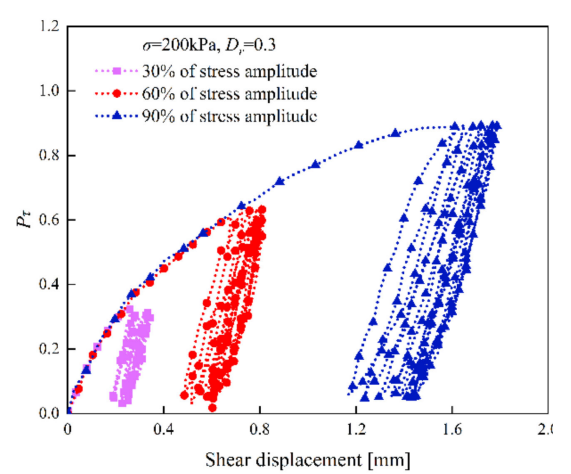

(a)

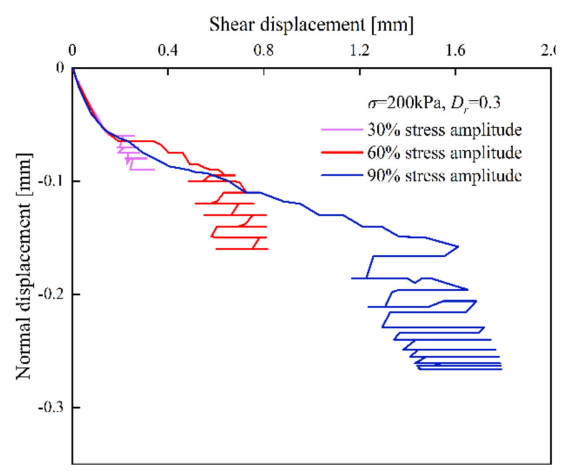

(d)

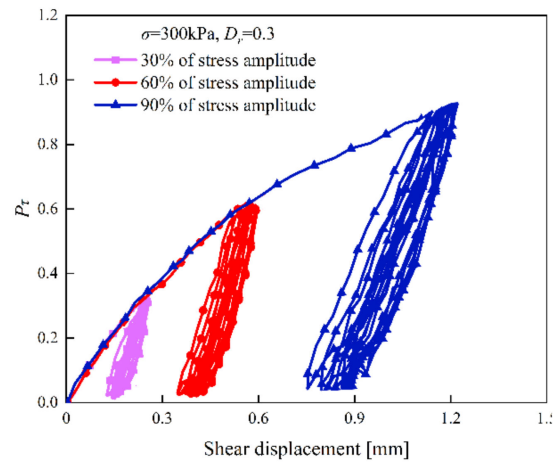

(b)

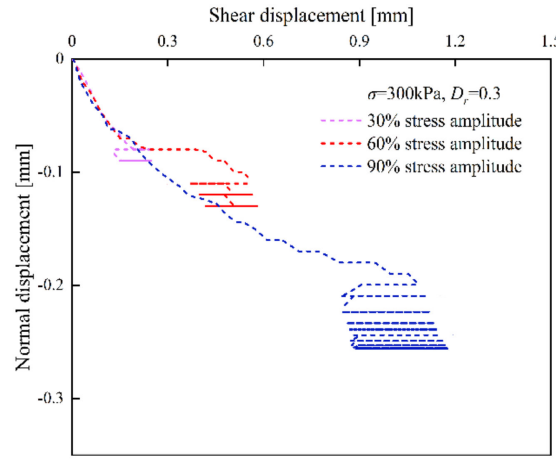

(e)

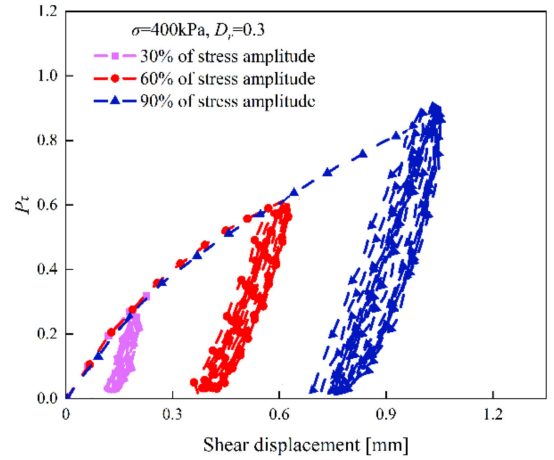

(c)

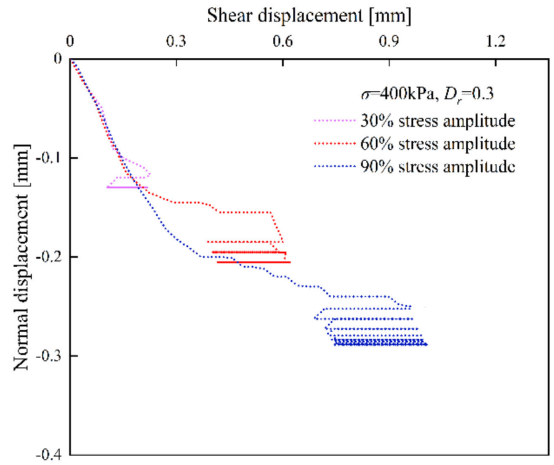

(f)

Figure 7. Comparison of morphological characteristics of sand-steel interface in cyclic shear test: $(\mathbf{a}, \mathbf{d}) \sigma=200 \mathrm{kPa}, R_{n 1}$; $(\mathbf{b}, \mathbf{e}) \sigma=300 \mathrm{kPa}, R_{n 1} ;(\mathbf{c}, \mathbf{f}) \sigma=400 \mathrm{kPa}, R_{n 1}$.

\subsubsection{Shear Displacement-Normal Displacement Curve}

The changes in shear stiffness and residual deformation in the above cycles will be discussed later in this article. In order to compare with the previous monotonic shear test research, Figure $7 \mathrm{~d}-\mathrm{f}$ show the shear displacement-normal displacement curve corresponding to the test results above. It can be seen from the test results that the loose sand is located on a relatively smooth interface. During the initial loading process, the curve is similar to the static loading situation described above, generally showing volume shrinkage. In the later dynamic loading process, the normal displacement of each cycle is much smaller than that of the initial loading stage, and it continues to develop. It is found that the final deformation accumulated during the dynamic loading phase exceeds that produced by the above-mentioned static test. The higher the stress level amplitude, the greater the accumulated normal deformation. In addition, the normal deformation is mainly affected by the normal stress, and the interface roughness has little effect on its deformation. As the normal stress increases, the total amount of normal deformation accumulated during dynamic loading decreases. Taking the stress level amplitude of $90 \%$ loose sand on the relatively smooth interface as an example, when the normal stress is $200 \mathrm{kPa}$, the cumulative normal deformation is $0.108 \mathrm{~mm}$. When the normal stress increases to $400 \mathrm{kPa}$, the accumulated normal deformation is reduced by $35 \%$. It can be seen that the normal displacement of the loose sand interface gradually decreases in each cycle. This corresponds to the tightness between the loading and unloading curves of the aforementioned shear displacement-shear stress ratio. The loading and unloading curve tend to be loose, the normal displacement produced by each cycle is larger, and the final cumulative normal deformation is larger. Additionally, notice that the normal displacement curve has a tendency to move continuously to the right, which means that residual deformation has occurred in the cycle. This is also consistent with the above analysis of residual deformation caused by inconsistent loading and unloading stiffness. 
The performance of dense sand in circulation is similar, except that the accumulated normal deformation is smaller than that of loose sand.

\subsection{Analysis and Discussion}

\subsubsection{Residual Deformation of Cyclic Shear}

The point in the shear displacement-shear stress ratio curve after each loading and unloading cycle is taken as the research base point. Through the normalization method, the ratio of $u_{s r}$ and $u_{s y}$ is used to measure the degree of residual deformation in this cycle test. Where $u_{s r}$ is the residual displacement accumulated after each cycle, $u_{s y}=\tau_{y} / K_{\text {in }}$ and $\tau_{y}$ is the peak strength in the monotonic shear test.

Figure 8 shows the most significant situation in which the residual deformation phenomenon occurs in the above-mentioned cycle, which is the $90 \%$ stress level amplitude. When the interface is relatively smooth, the residual displacements of loose sand and dense sand both increase with the increase in the number of cycles. However, the residual displacement increment between each cycle gradually decreases. As the normal stress increases, the residual deformation of the interface between loose sand and dense sand will decrease. When the normal stress is constant, the residual deformation at the interface of loose sand is larger than that of dense sand. For example, when loose sand is subjected to normal stresses of $200 \mathrm{kPa}$ and $400 \mathrm{kPa}$, the cumulative shear deformation after the 10th cycle increases by $8.92 \%$ and $5.08 \%$, respectively, compared with that after the first cycle. When the normal stress is both $200 \mathrm{kPa}$, the final residual deformation of loose sand and dense sand differs by $7.67 \%$. Figure $8 \mathrm{~b}$ reflects the residual deformation when the interface is rough. It is basically consistent with the morphological trend when the interface is relatively smooth. However, under the same conditions, the residual deformation of rough interface sand is smaller than that of the relatively smooth interface. This means that the residual deformation of the cohesionless soils in the cyclic shearing process gradually increases. Additionally, the weekly residual displacement increment gradually decreases. As the normal stress increases, the residual deformation of the same density sand will become smaller. Compared with dense sand, when the normal stress is the same, the residual deformation of loose sand will be greater. If the relative density of sand is the same as the normal stress, the residual deformation of the rough interface is smaller than that of the relatively smooth interface.

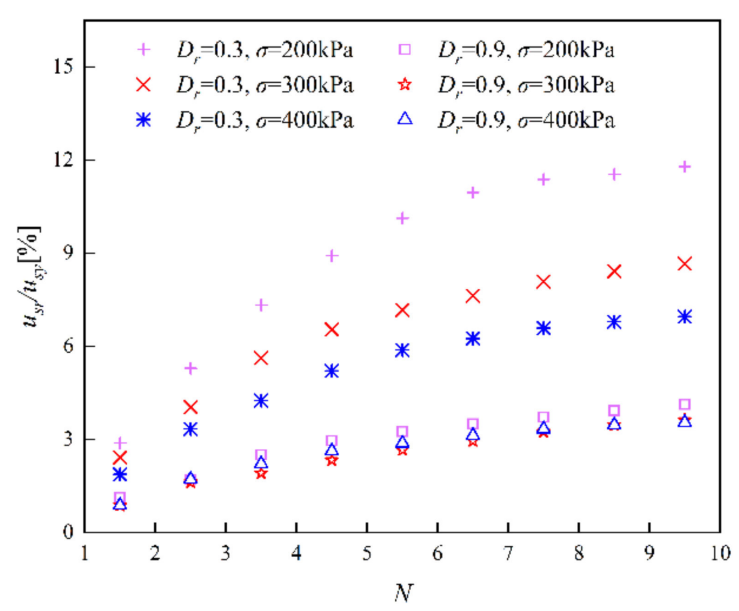

(a)

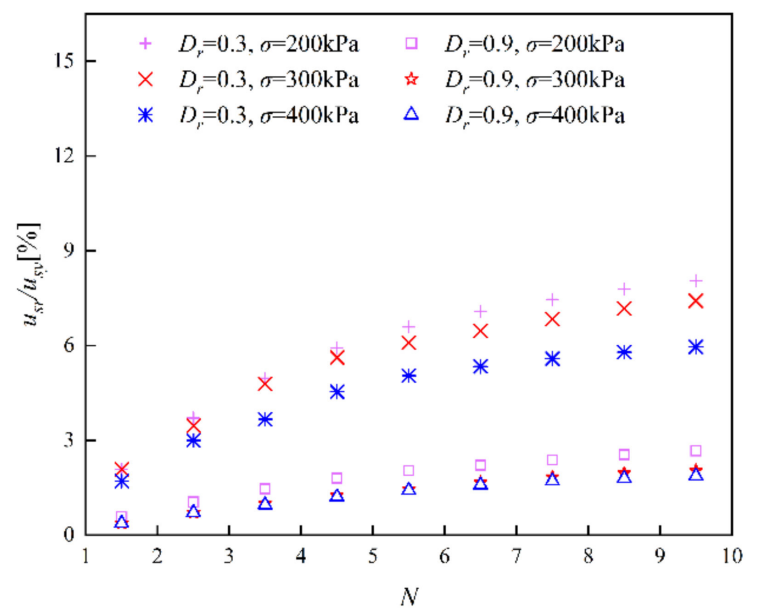

(b)

Figure 8. The development law of residual deformation with the number of cycles (Stress level amplitude: $90 \%$ ): (a) $R_{n 1}$. (b) $R_{n 3}$.

The residual deformation under different stress level amplitudes when the normal stress is controlled at $300 \mathrm{kPa}$ (Figure 9). It is observed that the residual deformation at the sand-steel interface at stress level amplitudes of $30 \%$ and $60 \%$ is extremely small. The proportion of residual deformation does not exceed $3 \%$ of the displacement that reaches 
the peak shear strength. Therefore, the residual deformation generated in the cycle for the stress level amplitude below $60 \%$ has very little impact on the actual project. Therefore, this article will not go into detail.

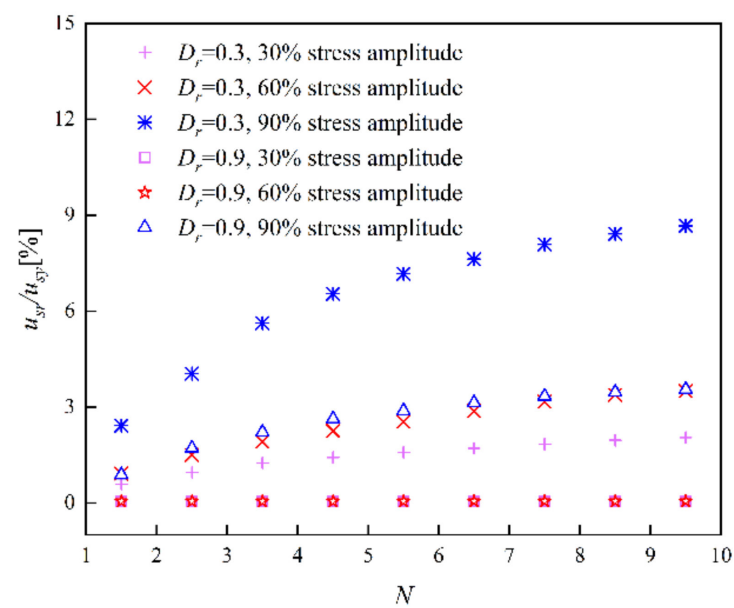

(a)

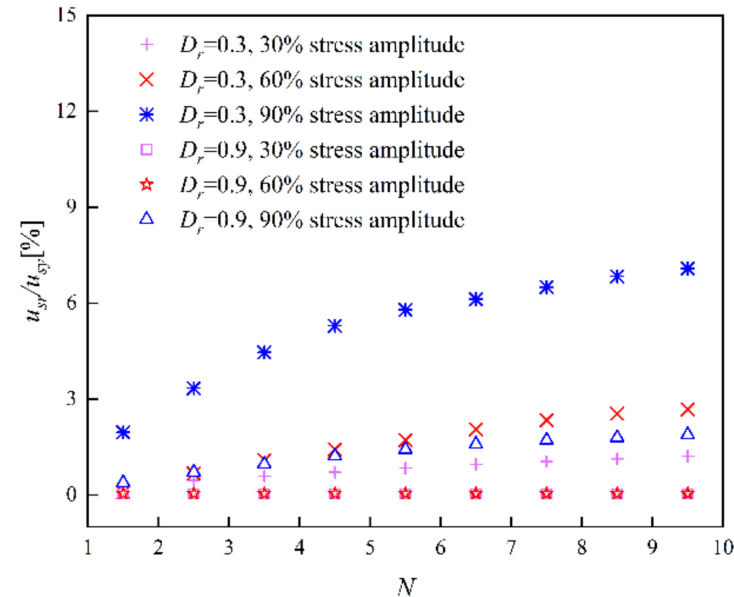

(b)

Figure 9. Influence of different stress level amplitudes on residual deformation: (a) $R_{n 1}$. (b) $R_{n 3}$.

The change in the trend of the residual deformation and the cumulative residual displacement increment is obtained above. The main reason for the residual deformation is the inconsistency of the shear stiffness during the cycle. In previous studies on the response of similar hysteresis loops, the secant stiffness of the loading and unloading hysteresis curves of Masing's model [22] was the same. Therefore, there is no residual deformation. On this basis, if the study uses the loading and unloading criteria proposed by Pyke [23] (the characteristic of the model is that the stiffness of each loading is only related to the current turning point), although it is also possible to simulate the case where the loading stiffness is less than the unloading stiffness, the loading stiffness is the same every time. This may cause excessive residual deformation. The phenomenon obtained in this experiment is the accumulation of residual deformation, and the increment of residual deformation gradually decreases. Therefore, both Masing and Pyke's models are flawed in the simulation of this experimental phenomenon. It is necessary to propose a new model to simulate this experimental phenomenon.

\subsubsection{Cyclic Loading and Unloading Shear Stiffness}

Comparing the initial loading stiffness in the cyclic test with the initial loading stiffness in the monotonic shear test above, the corresponding shear stiffness data are basically the same. Additionally, in the cyclic test, the initial loading phase curves of different stress level amplitudes almost overlapped on one curve. This also reflects the reliability of this monotonic shear test and cycle test. Due to the dense distribution of the loading and unloading curves in the cyclic test image, the shear stiffness of the cyclic loading and unloading curves is better reflected by the respective secant stiffness. The cyclic load and shear deformation incremental model shown in Figure 10 can be used to consider the change of the interface cyclic load path to construct a calculation method for the shear stiffness of the cyclic loading and unloading curve.

The shear stiffness of the Nth loading and unloading secants are:

$$
\begin{aligned}
K_{l N} & =\frac{\tau_{\text {max }}-\tau_{\text {min }}}{u_{\text {slNmax }}-u_{s N \text { min }}} \\
K_{u N} & =\frac{\tau_{\text {max }}-\tau_{\text {min }}}{u_{\text {suNmax }}-u_{\text {sNmin }}}
\end{aligned}
$$


where $K_{l N}$ is the secant shear stiffness of the loaded branch corresponding to the Nth cycle and $K_{u N}$ is the secant shear stiffness of the unloaded branch corresponding to the Nth cycle. $\tau_{\max }$ and $\tau_{\min }$ are the maximum and minimum interface shear stresses, respectively. $u_{\text {slNmax }}$ and $u_{\text {suNmax }}$ are the cumulative shear displacements of the maximum loading and unloading branches during the Nth cycle, respectively. $u_{s N \min }$ is the cumulative shear displacement of the minimum loading and unloading support during the Nth cycle.

According to formulas (4) and (5), the variation law of the secant shear stiffness of the interface cyclic loading and unloading branches with different relative roughness $\left(R_{n 1}\right.$, $R_{n 3}$ ) under different normal stresses can be calculated.

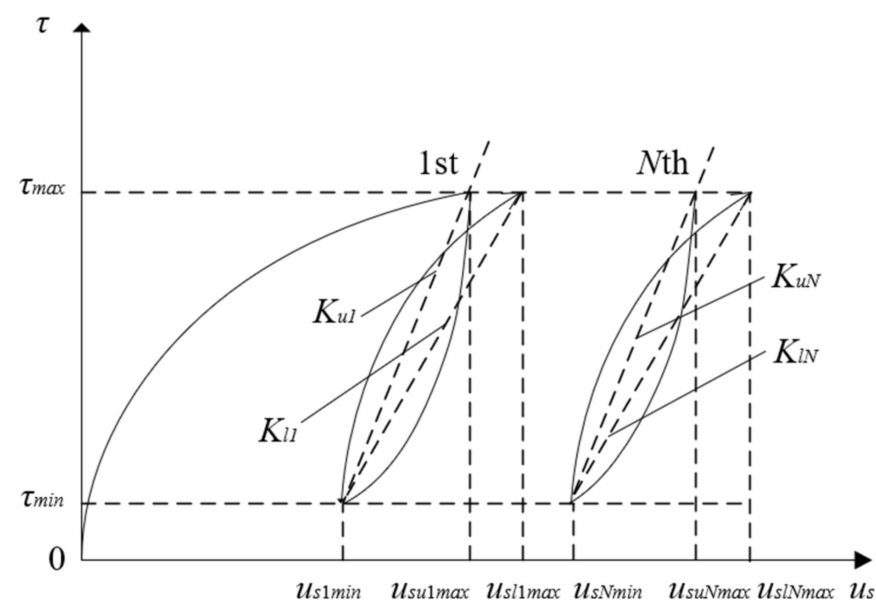

Figure 10. Calculating method of interface cyclic shear stiffness.

The secant shear stiffness of the loose sand loading curve on the interface of different relative roughness gradually increases with the increase in the number of cycles (Figure 11a). Additionally, the growth amplitude of its loading shear stiffness gradually decreases and finally the situation tends to be stable. For example, when $\tau_{\max }$ is $78.3 \mathrm{kPa}, K_{l 1}=156.35 \mathrm{kPa} \cdot \mathrm{mm}^{-1}, K_{l 2}=176.67 \mathrm{kPa} \cdot \mathrm{mm}^{-1}, K_{l 9}=228.28 \mathrm{kPa} \cdot \mathrm{mm}^{-1}$, and $K_{l 10}=229.62 \mathrm{kPa} \cdot \mathrm{mm}^{-1}$, it can be seen that the loading shear stiffness of the 10th cycle is $30.21 \%$ higher than that of the first cycle. $K_{l 2}$ to $K_{l 1}$ is about $13 \%$ higher, and $K_{l 10}$ to $K_{l 9}$ is only $0.59 \%$ higher. It is also found that the loading stiffness of the same relative density sand increases with the increase in the normal stress. However, the growth rate of its loading stiffness decreases. The main reason is that the greater the normal stress, the greater the initial shear stiffness. Moreover, the loading shear stiffness of sand under a rough interface is generally greater than that of the relatively smooth interface. It can be seen from Figure $11 \mathrm{~b}$ that the loading stiffness change trend of dense sand is basically the same as that of loose sand. The difference is that the loading shear stiffness of dense sand increases more slowly. If the normal stress and the interface roughness are the same, the loading stiffness of dense sand is generally higher than that of loose sand. This shows that both loose sand and dense sand show a cyclic hardening tendency during the cyclic shearing process. This is consistent with the change rule of residual deformation mentioned above. The loading stiffness increases with the increase in the number of cycles, and the unloading stiffness is almost unchanged, resulting in a continuous increase in residual deformation. In addition, the increase in the loading stiffness and residual displacement increment per cycle continuously decreases.

Looking back at the unloading shear stiffness, Figure $11 \mathrm{c}, \mathrm{d}$ show that the secant shear stiffness of the unloading curve does not increase or attenuate significantly during the cycle. However, the unloading shear stiffness of each set of tests is greater than the loading shear stiffness. When comparing the initial loading stiffness of each cycle test with the tangent stiffness of the last unloading curve, it is found that the final unloading stiffness of each group of tests is greater than its initial loading stiffness. This means that the unloading shear stiffness in each cycle test is always greater than its loading shear stiffness. 
Additionally, the loading shear stiffness gradually increases with the increase in the number of cycles, but the loading shear stiffness will not exceed the unloading shear stiffness.

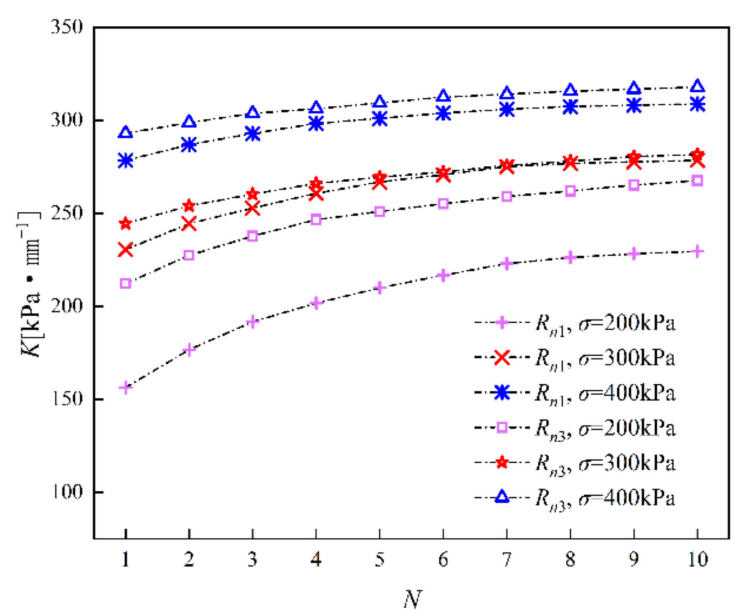

(a)

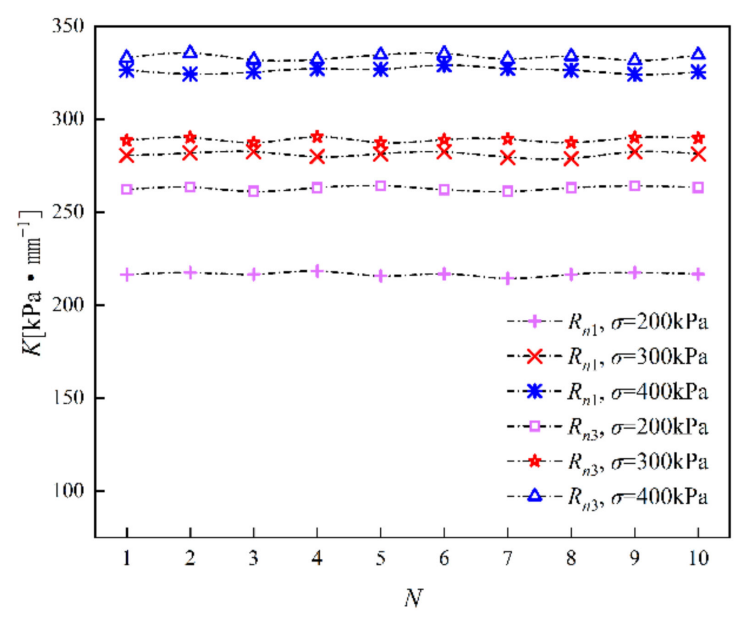

(c)

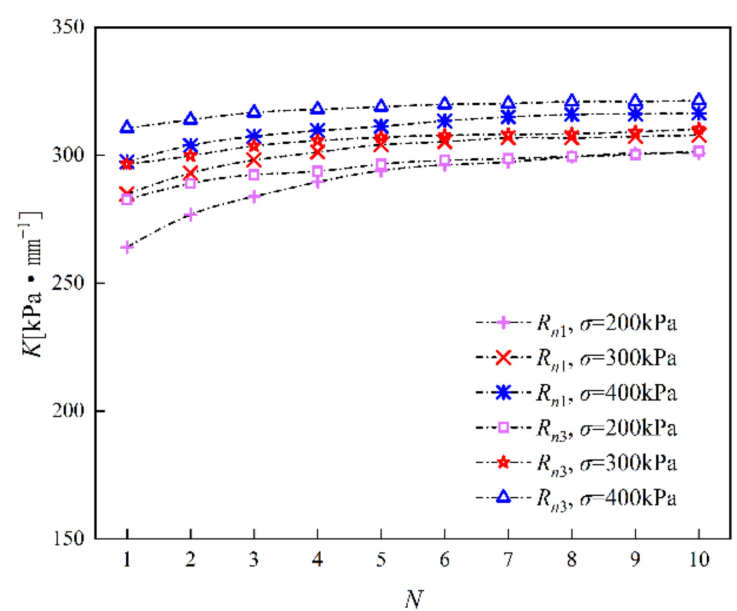

(b)

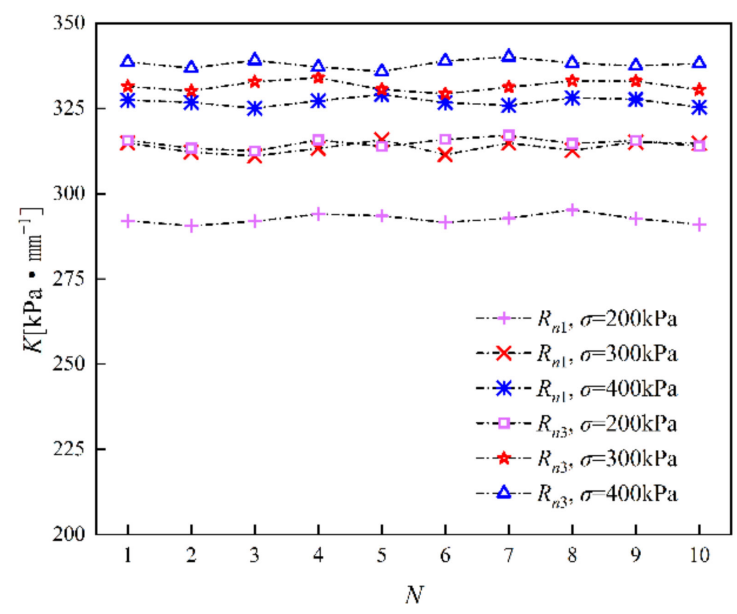

(d)

Figure 11. The development law of interface cyclic loading and unloading shear stiffness with the number of cycles (stress amplitude level: 90\%). (a) Cyclic loading, $D_{r}=0.3$. (b) Cyclic loading, $D_{r}=0.9$. (c) Cyclic unloading, $D_{r}=0.3$. (d) Cyclic unloading, $D_{r}=0.9$.

\subsubsection{Loading and Unloading Shear Stiffness under Different Stress Level Amplitudes}

In the tests, the normal stress is controlled at $300 \mathrm{kPa}$ to observe the changing trend of cyclic loading and unloading stiffness under different stress level amplitudes (Figure 12). The development trend of the curve shape of the cyclic loading stiffness of loose sand with stress level amplitudes of $30 \%$ and $60 \%$ is almost the same as the abovementioned $90 \%$ change law. They all show a trend of increasing loading stiffness, but their increasing range gradually decreases. For example, the second loading stiffness of loose sand with a 30\% stress level amplitude at the relatively smooth interface is about $1.9 \%$ higher than the first loading, while the tenth loading stiffness is only about $0.2 \%$ higher than the ninth loading. In addition, when the interface roughness is the same, as the stress level amplitude increases, the overall loading stiffness decreases. Additionally, under the same stress level amplitude, the loading stiffness of the relatively smooth interface is generally less than that of the rough interface. The behavior of dense sand is different. The loading stiffness at the $30 \%$ and $60 \%$ stress level amplitude hardly increases or decays. This means that at low or medium stress level amplitude, the load-shear stiffness of relatively dense cohesive soils hardly changes during the cycle. 


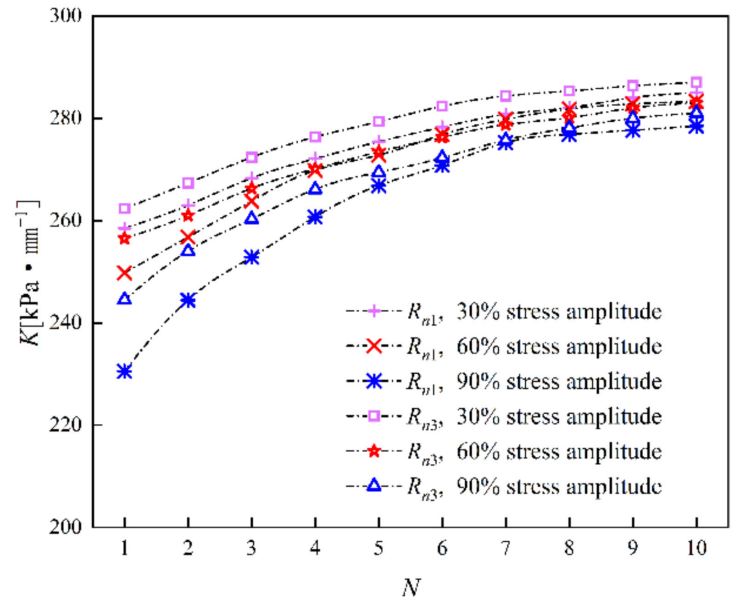

(a)

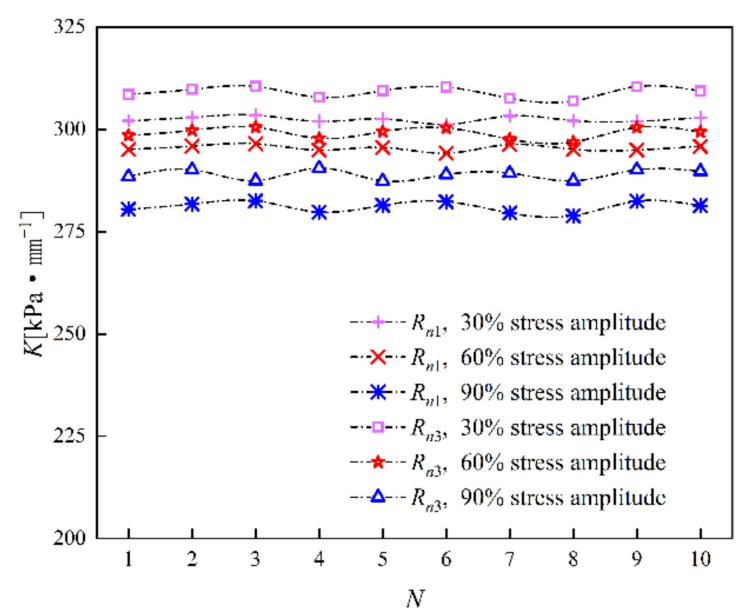

(c)

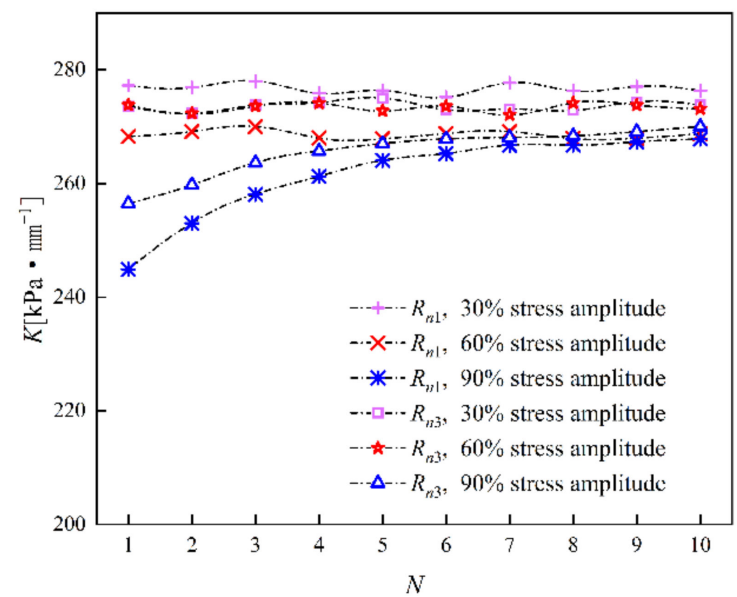

(b)

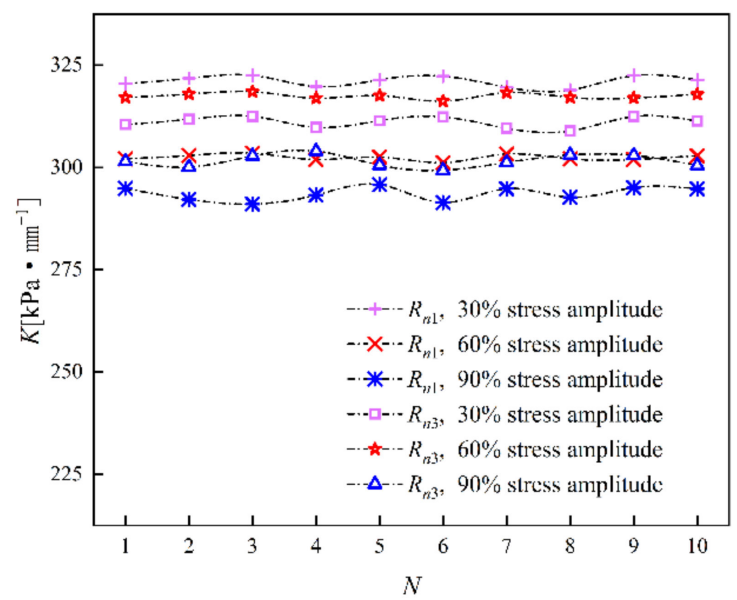

(d)

Figure 12. The influence of different stress level amplitudes on the shear stiffness of cyclic loading and unloading. (a) Cyclic loading, $D_{r}=0.3$. (b) Cyclic loading, $D_{r}=0.9$. (c) Cyclic unloading, $D_{r}=0.3$. (d) Cyclic unloading, $D_{r}=0.9$.

Through Figure 12c,d, it is found that the unloading stiffness of different stress level amplitude has no obvious fluctuation during the cycle. Additionally, as the stress level amplitude increases, the overall loading stiffness decreases. Under the same stress level amplitude, the loading stiffness of the rough interface is generally greater than that of the relatively smooth interface. It is worth mentioning that the loading stiffness of loose sand or dense sand under the same stress level amplitude is always lower than the unloading stiffness. Additionally, with the continuous increase of loading stiffness, it will approach and unload stiffness. This point is consistent with the above conclusion about the loading and unloading stiffness of $90 \%$ stress level amplitude.

Figure 13 shows the unloading stiffness of the last cycle under different stress level amplitudes. It can be seen from the figure that whether it is loose sand or dense sand, under the same normal stress, the higher the stress level amplitude, the lower the final unloading stiffness. In addition, the increase in normal stress or the relative density of sand will increase the unloading stiffness. This point is almost consistent with the above experimental conclusions. Therefore, it can be seen from the comprehensive analysis of static and dynamic tests that the loading stiffness of the sand-steel interface in the cyclic shear test continues to increase, and the unloading stiffness hardly changes. The higher the stress level amplitude, the lower the corresponding loading and unloading stiffness. Additionally, the unloading stiffness is always greater than the initial stiffness. As the cycle 
increases, the loading stiffness continues to increase, and it may eventually approach the unloading stiffness.

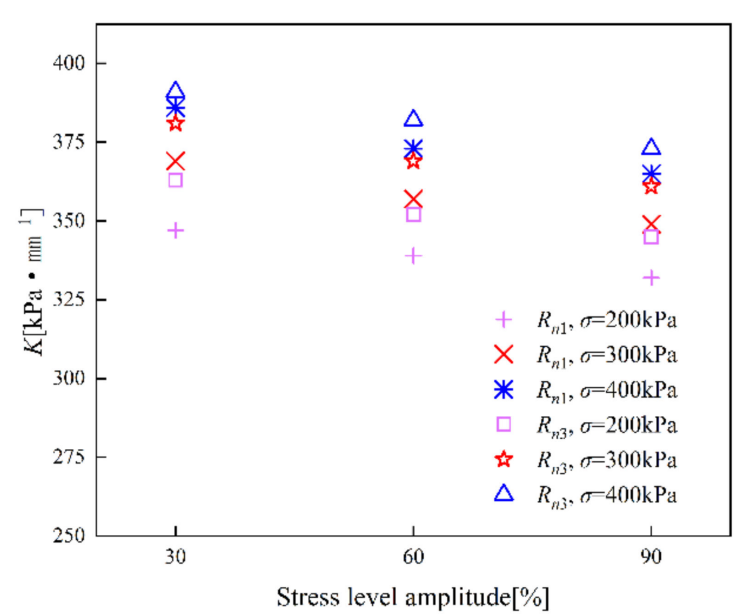

(a)

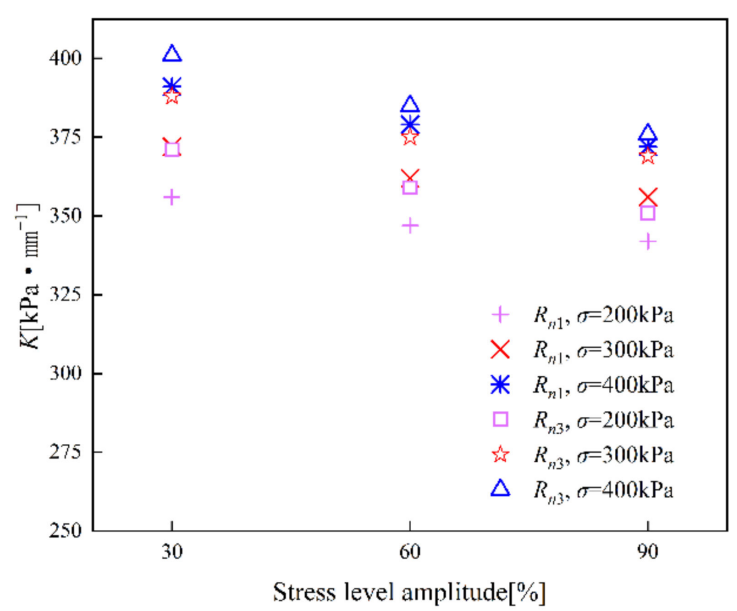

(b)

Figure 13. Final unloading stiffness of different stress level amplitudes. (a) $D_{r}=0.3$. (b) $D_{r}=0.9$.

\section{Methodology}

In this paper, the shear behavior of the sand-structure interface was studied through static and dynamic tests. According to the empirical formula of initial shear modulus [29] proposed previously, and fitting the results of this experiment, a formula for calculating the initial shear stiffness of the interface between sand and structure was proposed. This formula mainly considered the influence of factors such as the relative density of the sand, the roughness of the interface, and the normal stress on the initial shear stiffness. Then, this research combined the problems that might be encountered in the actual project and conducted the cyclic shear test under the influence of the initial shear stress. The normalization method was mainly used to present the shape of the loading and unloading curve and the development law of the cumulative normal deformation.

Taking the point after each cycle of loading and unloading cycles as the research base point, $u_{s r} / u_{s y}$ was used to measure the degree of residual deformation and the development trend produced in the cycle test. It was found that the residual deformation of loose sand was greater than that of dense sand. The secant stiffness of the loading and unloading curve was defined to analyze the behavior of loading and unloading stiffness during the cycle. The analysis results showed that the unloading stiffness is always greater than the loading stiffness, and the loading stiffness increases with the cycle, and may eventually approach the unloading stiffness. In addition, on this basis, the comparative tests of cyclic shear on the sand-steel interface under the action of different stress level amplitudes were carried out. In this work, the variation of loading and unloading stiffness and its residual deformation under different stress level amplitudes were discussed.

\section{Conclusions}

In this study, a series of tests were conducted on the monotonic and cyclic shear of the sand-steel interface. The mechanical properties of the shear behavior of the interface between the sand and structure are analyzed. The conclusions are as follows:

1. In the monotonic shear test, when the interface is relatively smooth, the shear stressshear displacement curves of loose sand and dense sand both show strain hardening characteristics. When the interface is rough, there will be strain softening for dense sand. The initial shear stiffness of the sand-steel interface increases with the increase in normal stress, interface roughness, or the relative density of sand.

2. Both loose sand and dense sand generally show volume shrinkage during the cycle. The initial loading process is similar to the case of static loading. In the later stages 
of dynamic loading, the shear shrinkage per cycle is relatively small and continues to develop. Additionally, as the normal stress increases, the accumulated normal deformation during dynamic loading decreases.

3. When the stress level amplitude reaches $90 \%$, residual deformation will occur during the cyclic shearing process. For loose sand in particular, the maximum deformation exceeds $u_{s r} / u_{s y}$ of $12 \%$. However, when the stress level amplitude is less than or equal to $60 \%$, there is almost no residual shear deformation.

4. The unloading stiffness of the interface between the sand and the structure is always greater than the initial loading stiffness. Additionally, with the increase in the number of cycles, the loading stiffness continues to increase, and it may eventually approach the unloading stiffness. In addition, the increase in normal stress and interface roughness can improve the loading and unloading stiffness.

Author Contributions: Conceptualization, P.Z. and K.F.; methodology, P.Z. and K.F.; formal analysis, P.Z. and K.F.; investigation, P.Z. and S.D.; resources, P.Z. and K.F.; data curation, P.Z. and S.D.; writing — original draft preparation, P.Z. and K.F.; writing — review and editing, P.Z. and K.F.; funding acquisition, K.F. All authors have read and agreed to the published version of the manuscript.

Funding: This research was funded by the National Natural Science Foundation of China (Grant Number 51778557).

Institutional Review Board Statement: Not applicable.

Informed Consent Statement: Not applicable.

Data Availability Statement: The data presented in this study are available on request from the corresponding author. The data are not publicly available due to privacy concerns.

Acknowledgments: The authors are grateful for the technical support provided by the School of Building Science and Engineering, Yangzhou University, and also want to thank Applied Sciences Editorial Office for their patient editing and support during the writing of this manuscript.

Conflicts of Interest: The authors declare no conflict of interest.

\section{References}

1. Zeghal, M.; Edil, T.B. Soil structure interaction analysis: Modeling the interface. Can. Geotech. J. 2002, 39, 620-628. [CrossRef]

2. Hu, L.; Pu, J. Testing and Modeling of Soil-Structure Interface. J. Geotech. Geoenviron. Eng. 2004, 130, 851-860. [CrossRef]

3. Lashkari, A. Modeling of sand-structure interfaces under rotational shear. Mech. Res. Commun. 2010, 37, 32-37. [CrossRef]

4. Yang, Z.X.; Jardine, R.J.; Zhu, B.T.; Foray, P.; Tsuha, C. Sand grain crushing and interface shearing during displacement pile installation in sand. Géotechnique 2010, 60, 469-482. [CrossRef]

5. Ho, T.; Jardine, R.J.; Anh-minh, N. Large-displacement interface shear between steel and granular media. Géotechnique 2011, 61, 221-234. [CrossRef]

6. Peng, H.; Kong, G.; Liu, H.; Abuel-Naga, H.; Hao, Y. Thermo-mechanical behaviour of floating energy pile groups in sand. J. Zhejiang Univ. Sci. A 2018, 19, 638-649. [CrossRef]

7. Guerdouh, D.; Khalfallah, S. Soil-structure interaction effects on the seismic performance of frame structures. J. Constr. 2019, 18, 349-363. [CrossRef]

8. Kwon, S.Y.; Yoo, M. Study on the Dynamic Soil-Pile-Structure Interactive Behavior in Liquefiable Sand by 3D Numerical Simulation. Appl. Sci. 2020, 10, 2723. [CrossRef]

9. Isaev, O.N.; Sharafutdinov, R.F. Soil Shear Strength at the Structure Interface. Soil Mech. Found. Eng. 2020, 57, 139-146. [CrossRef]

10. Forcellini, D. Soil-structure interaction analyses of shallow-founded structures on a potential-liquefiable soil deposit. Soil Dyn. Earthq. Eng. 2020, 133, 106108. [CrossRef]

11. Forcellini, D. Numerical simulations of liquefaction on an ordinary building during Italian (20 May 2012) earthquake. Bull. Earthq. Eng. 2019, 17, 4797-4823. [CrossRef]

12. Lopez-Caballero, F.; Modaressi-Farahmand-Razavi, A. Numerical simulation of mitigation of liquefaction seismic risk by preloading and its effects on the performance of structures. Soil Dyn. Earthq. Eng. 2013, 49, 27-38. [CrossRef]

13. Borana, L.; Yin, J.-H.; Singh, D.N.; Shukla, S.K.; Tong, F. Direct Shear Testing Study of the Interface Behavior between Steel Plate and Compacted Completely Decomposed Granite under Different Vertical Stresses and Suctions. J. Eng. Mech. 2018, 144, 4017148. [CrossRef]

14. Martinez, A.; Frost, J.D. The influence of surface roughness form on the strength of sand-structure interfaces. Géotechnique Lett. 2017, 7, 104-111. [CrossRef] 
15. Pra-ai, S.; Boulon, M. Soil-structure cyclic direct shear tests: A new interpretation of the direct shear experiment and its application to a series of cyclic tests. Acta Geotech. 2017, 12, 107-127. [CrossRef]

16. $\mathrm{Gu}, \mathrm{X}$.; Chen, Y.; Huang, M. Critical state shear behavior of the soil-structure interface determined by discrete element modeling. Particuology 2017, 35, 68-77. [CrossRef]

17. Uesugi, M.; Kishida, H.; Uchikawa, Y. Friction between dry sand and concrete under monotonic and repeated loading. Int. J. Rock Mech. Min. Sci. Geomech. Abstr. 1990, 27, 338. [CrossRef]

18. Potyondy, J.G. Skin Friction between Various Soils and Construction Materials. Géotechnique 1961, 11, 339-353. [CrossRef]

19. Hamid, T.B.; Miller, G.A. Shear strength of unsaturated soil interfaces. Can. Geotech. J. 2009, 46, 595-606. [CrossRef]

20. Desai, C.S.; Drumm, E.C.; Zaman, M.M. Cyclic Testing and Modeling of Interfaces. J. Geotech. Eng. 1985, 111, 793-815. [CrossRef]

21. Kwak, C.W.; Park, I.J.; Park, J.B. Dynamic shear behavior of concrete-soil interface based on cyclic simple shear test. KSCE J. Civ. Eng. 2014, 18, 787-793. [CrossRef]

22. Masing, G. Eigenspannungen und verfestigung beim messing. In Proceedings of the 2nd International Congress of Applied Mechanics, Zurich, Switzerland, 12-17 September 1926; pp. 332-335.

23. Pyke, R.M. Nonlinear Soil Models for Irregular Cyclic Loadings. J. Geotech. Eng. Div. 1979, 105, 715-726. [CrossRef]

24. Chang, K.-H.; Jeon, J.-T.; Lee, C.-H. Effects of residual stresses on the uniaxial ratcheting behavior of a girth-welded stainless steel pipe. Int. J. Steel Struct. 2016, 16, 1381-1396. [CrossRef]

25. Adamchuk, M.P.; Borodii, M.V.; Selin, O.M.; Stryzhalo, V.O. Development of the Model for Cyclic Plasticity to Describe the Ratcheting Effect Under Non-Proportional Asymmetric Loading. Strength Mater. 2016, 48, 251-258. [CrossRef]

26. Chen, X.; Chen, X. Study on ratcheting effect of pressurized straight pipe with local wall thinning using finite element analysis. Int. J. Press. Vessel. Pip. 2016, 139-140, 69-76. [CrossRef]

27. Ferezqi, H.Z.; Shariati, M.; HadidiMoud, S. The Assessment of Elastic Follow-Up Effects on Cyclic Accumulation of Inelastic Strain Under Displacement-Control Loading. Iran J. Sci. Technol. Trans. Mech. Eng. 2018, 42, 127-135. [CrossRef]

28. Sarkar, P.P.; Chakraborti, P.C. Uniaxial Ratcheting Behavior of a Weather-Resistant Rail Steel: Effect of Mean Stress and Stress Amplitude. J. Mater. Eng. Perform. 2020, 29, 2936-2946. [CrossRef]

29. Hardin, B.O.; Drnevich, V.P. Shear Modulus and Damping in Soils: Design Equations and Curves. J. Soil Mech. Found. Div. 1972, 98, 667-692. [CrossRef]

30. Punetha, P.; Mohanty, P.; Samanta, M. Microstructural investigation on mechanical behavior of soil-geosynthetic interface in direct shear test. Geotext. Geomembr. 2017, 45, 197-210. [CrossRef]

31. Wang, J.; Ying, M.-J.; Liu, F.-Y.; Fu, H.-T.; Ni, J.-F.; Shi, J. Effect of Particle-Size Gradation on Coarse Sand-Geotextile Interface Response in Cyclic and Postcyclic Direct Shear Test. Adv. Civ. Eng. 2020, 2020, 1-11. [CrossRef]

32. Kou, H.; Diao, W.; Zhang, W.; Zheng, J.; Ni, P.; JANG, B.-A.; Wu, C. Experimental Study of Interface Shearing between Calcareous Sand and Steel Plate Considering Surface Roughness and Particle Size. Appl. Ocean. Res. 2021, 107, 102490. [CrossRef]

33. Su, L.-J.; Zhou, W.-H.; Chen, W.-B.; Jie, X. Effects of relative roughness and mean particle size on the shear strength of sand-steel interface. Measurement 2018, 122, 339-346. [CrossRef] 